\title{
Physical and hydrodynamic characteristics of a dairy shed waste stabilisation pond system
}

\author{
Julian Fyfe, Jane Smalley, D. Hagare and M. Sivakumar
}

Sustainable Water and Energy Research Group, Faculty of Engineering, University of Wollongong, Australia

\begin{abstract}
Waste stabilization pond systems are widely used to treat animal wastes under highly variable hydraulic loading regimes. These systems have received limited research attention with regards to their hydrodynamic behaviour and the potential impact of shock hydraulic loading on their performance. In this study a two-stage dairy shed waste stabilisation pond system was topographically surveyed to determine the physical shape and the theoretical hydraulic retention time (HRT) of each pond, as well as the extent of sludge accumulation in the primary pond. The primary pond was then subjected to a series of drogue tracking runs whereby weighted floating survey targets with submerged 'sails' were tracked during their movement through the pond at times of peak flow in order to characterise the hydrodynamic behaviour of the pond. The full capacity volumes of the primary and secondary ponds were calculated to be $1285 \mathrm{~m}^{3}$ and $2391 \mathrm{~m}^{3}$, respectively. Sludge had been accumulating in the primary pond at a rate of $0.73 \mathrm{~m}^{3} / \mathrm{d}$ over a period of 2.4 years and this has reduced the active treatment volume of the pond to $657 \mathrm{~m}^{3}$. Based on mean outflow, the HRTs of the ponds were $40 \mathrm{~d}$ and $137 \mathrm{~d}$, respectively. The drogue runs revealed a vortex-like mixing pattern within the pond with higher velocities around the perimeter of the pond between the inlet and outlet, and lower velocities in the centre of the pond. In-pond velocities seemed relatively high in comparison with those from other drogue studies of larger ponds and the surging inflow caused the formation of a flow 'jet' that potentially contributed to significant short-circuiting. The range of influence of this flow jet, however, was limited to within $15 \mathrm{~m}$ of the inlet, suggesting that shortcircuiting would be likely to occur only under certain high inflow conditions.
\end{abstract}

\section{INTRODUCTION}

Current best practice in the management of dairy shed (or farm dairy) waste in Australia utilises stabilisation ponds to hold and treat wastewater prior to recycling the effluent via application to land and/or effluent reuse as flush water for the holding yard. Variations on the same theme are widely used to manage other forms of animal wastes in agriculture such as that from piggeries and poultry farms. In order to determine the ongoing effectiveness and workability of such systems a case study has been undertaken on a 300-head dairy farm in the Southern Highlands region of NSW, Australia. The waste management system comprises a flood wash system for hydraulically flushing the holding yard with reclaimed effluent. The wastewater from the flood wash and from manual hosing of the dairy drains to a solids separation sump (solids trap), the effluent from which then flows sequentially to a primary anaerobic pond and then a secondary facultative pond. Supernatant from the facultative pond is pumped back to a holding tank for reuse in the next flood wash of the dairy.

One of the first activities of the case study was to conduct a topographic survey of the pond system in order to determine the true dimensions and capacity of the system. This also involved measuring the level of accumulated sludge in the primary pond to quantify the portion of active volume lost to sludge and to approximate a rate of sludge accumulation from the time the system came on-line. Once the physical nature of the pond system was established, it was sought to characterise the hydrodynamic nature of the primary stage of the pond system. It was already understood that flow into to the primary pond was highly variable comprising brief surges of high flow interspersed with longer lulls of low flow. To examine the impact of such erratic hydraulic loading on in-pond mixing, a series of drogue tracking experiments were conducted. Drogue tracking was favoured over the more established tracer dispersion method of hydraulic analysis (eg. Torres et al, 1997; Peña et al., 2000; Torres et al., 2000) on account of its simplicity and low cost, as well as significant technical complications associated with using chemical tracers in a full scale two-stage 
pond system. Drogues tracking has been successfully employed in the study of in-pond flow velocities in stabilisation ponds by Shilton and Kerr (1999) and Barter (2003). Primarily it has been applied to determine predominant flow paths and approximate in-pond flow velocities. Limitations of the method include the two-dimensional nature of drogue movement, the potential interference of wind and the inability to extrapolate the results of drogue tracking to determine actual residence times. Nonetheless, drogue tracking can provide useful insight into predominant mixing pattern of a pond, and also the incidence and extent of short-circuiting and the presence of dead zones within a pond. Moreover it presents a Lagrangian approach to the measurement of fluid pathways and velocities that dispersion studies cannot offer. Alternatively, computational fluid dynamics (CFD) modelling has been used to investigate the hydrodynamic behaviour of various pond configurations (eg. Wood et al., 1995; Salter et al., 2000; Sweeney et al., 2003; Vega et al., 2003) however this can be a complex, time-consuming and sometimes problematic exercise (see Wood et al., 1998), and one that still requires calibration and verification with some form of data gathered from the field.

There has been very little research into the hydraulic nature and performance of stabilisation ponds designed and built to the specifications required for the treatment of dairy shed waste. Typically ponds of this type have long residence times ( $>60 \mathrm{~d}$ ) to accommodate the high organic loading of the influent wastewater and to provide enough storage to hold wastewater (and rainfall) during periods of high rainfall when effluent cannot be irrigated to land. Hydraulic loading to primary ponds follows the farm milking regime, which most commonly consists of morning and afternoon milking sessions. During milking inflow is consistently low as wastewater mostly comes from manual hosing in the dairy. At the end the end of the milking session, however, the holding yard is cleaned by a large hydraulic flush, or flood wash. This flood wash generates a high peak flow, amounting to a significant shock loading to the primary pond, which could potentially contribute to, if not cause, short-circuiting.

\section{METHODOLOGY}

The physical characteristics of the stabilisation pond system including the shape, volume and theoretical retention time of each pond were determined from data gathered through a topographical survey. Two permanent traverse stations formed a line of reference for the survey which incorporated a combination of radiation and coordinate contour surveying techniques. The traverse stations were selected on the basis of visibility and proximity to the survey features and were mapped using a sub-10m geographic positioning system (Trimble XR Pro receiver). A Leica TN $400 \mathrm{~N}$ electronic total station and a wandering reflector staff were used to conduct the survey. Points sighted in the topographical survey were simultaneously recorded using the GPS unit in order to provide a check for the survey data and to map the site features more generally. The relief of the pond embankments was surveyed first by profiling the rise and fall of the crests on each side of the pond, and then by following distinct contour lines around the pond perimeter. The water perimeter of each pond was similarly traced and also incorporated as a contour level.

The pond basin and the depth of the sludge blanket in the primary pond were surveyed and measured using a specially-designed column sampling device similar to that described in Pearson et al. (1987) as the reflector staff. The target holder manoeuvred across the water surface of the pond in a small dinghy using a rope secured across the breadth of the pond. Using the GPS unit as a guide, the target holder would move to points in an approximate grid and place the reflective target atop of the column sampler as it was lowered to the bottom of the pond. The length of the column sampler was adjustable in order to accommodate the varying depth of the ponds, thus the length of the sampler was recorded with each target sighting. The depth of the sludge was determined by raising the transparent polycarbonate sampler out of the water and viewing the stratification of its contents in reference to depth markings on the tube. 
Drogue tracking experiments were carried out subsequent to the surveying of the ponds on four separate occasions when weather conditions were suitable (no rain and light to no wind). Several drogue designs based on the Shilton and Kerr (1999) design were first trialled in the field before a final design was selected for the experiment. The finished drogue (pictured in Figure 1) incorporated polystyrene floats that were kept as small as feasibly possible and were weighed down using small lead weights to limit wind-induced movement. The optimum quantity of lead weight relative to float size was determined by trial and error. The drogue 'sails' were fabricated from lightweight plastic board and weighed down again using lead weights. The sails were suspended from the surface float by nylon fishing line threaded through lengths of polyethylene irrigation tube that ensured that the line could not become entangled with obstacles such as kikuyu grass overgrowth and other drogues in the pond. The depth of the sail was chosen based on the depth of sludge determined from the surveying. Whilst in the middle region of the pond there was up to two meters of water above the sludge blanket, around the edge of the pond, the sludge level came within $1 \mathrm{~m}$ of the water surface. Thus a total sail length of about $0.5 \mathrm{~m}$ was considered appropriate, particularly in light of the findings of Shilton and Kerr (1999) that flow velocities were reasonably uniform through different depths.

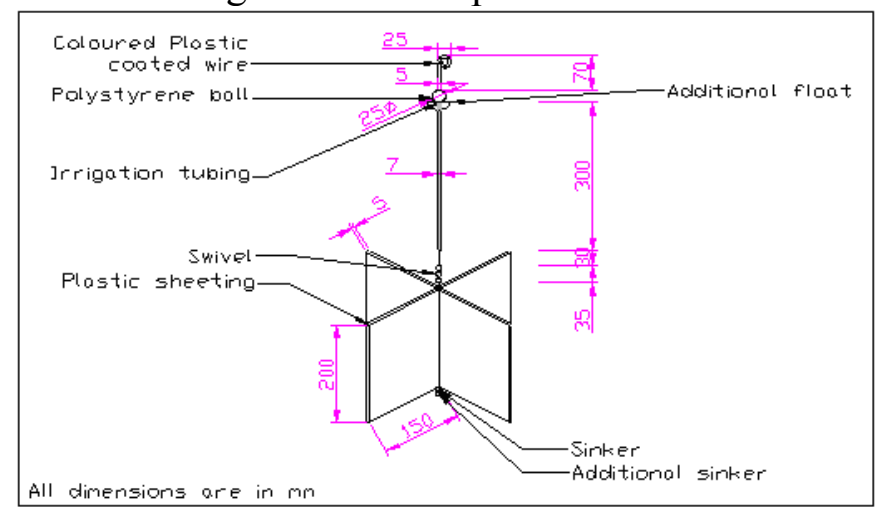

Figure 1 Drogue design used in field experiments.

The drogue experiments involved tracking by survey triangulation the movement through the ponds of strategically placed drogues during peak hydraulic loading. Peak flow conditions were generated by releasing a flood wash for each experimental run. The quantity of water released in the flood wash depended on the operator and the level of cleaning required (of the yard) and was measured using a pressure sensor depth gauge (Greenspan CTDP300) deployed in the holding tank. To ensure maximum flow through to the pond the screen in the solids trap was manually cleared at the commencement of the run. Flow into and out of the pond was gauged through rated flumes mounted with Milltronics probe level monitors for stage measurement, the data from which were recorded using a Campbell Scientific model CR10X data logger. Prior to each experimental run, scum on the pond surface that could potentially interfere with the movement of the drogue floats was removed by dragging a rope across the water surface.

For the majority of the experimental runs, the drogues were placed in the immediate path of the incoming flow, within a few metres of the inlet. Two additional runs were conducted with the drogues placed several metres to the north of the inlet beyond the influence of the inflow trajectory. Timing of the run and drogue tracking commenced with the release of the flood wash. Drogue locations were surveyed at varying intervals, depending on the rapidity of their movement. They were sighted from two stations, one equipped with the TN400N total station, the other with a Leica T100 theodolite. Being a field-based activity, the conditions of the experiment were very difficult to control, placing significant constraints on the successful execution of the experiments. A number of attempts had to be abandoned due to poor weather conditions. In the end a total of eight successful 
runs were conducted over the four days. Each run comprised the tracking the movement of two drogues, producing a total of sixteen drogue trails.

\section{RESULTS AND DISCUSSION Topographical survey}

Data from the topographical survey were collated and processed in spreadsheets and then digitised using Surfer Version 8.05 (Golden Software Inc., 2004). The digitised data sets were used to produce three dimensional contour (surface) maps and to calculate actual volume of the ponds. Figure 2 presents the surface maps of the primary (anaerobic) pond with and without sludge and the secondary (facultative) pond. The holding capacity of the facultative pond based on the high water indicator (elevation AHD $665.87 \mathrm{~m}$ ) was calculated to be $2391 \mathrm{~m}^{3}$. This capacity is $41 \%$ larger than the volume specified in the design, mainly due to the depth of the pond which reaches a maximum of $2.3 \mathrm{~m}$ as opposed to the design maximum depth of $1.2 \mathrm{~m}$. At the time of the survey the liquid volume of the facultative pond was $2136 \mathrm{~m}^{3}$, although this value would vary with water level which depends on the amount of effluent being pumped to irrigation relative to the hydraulic loading. The total capacity of the anaerobic pond was calculated to be $1285 \mathrm{~m}^{3}$, which is again higher than the design volume of $1000 \mathrm{~m}^{3}$. The active liquid volume of the anaerobic pond was rendered much smaller due to the presence and continuing accumulation of sludge which at the time of the survey had reduced the active treatment volume by $49 \%$ to $657 \mathrm{~m}^{3}$. At the time of the survey, the pond system had been in operation for 860 days, giving a sludge accumulation rate of $0.73 \mathrm{~m} / \mathrm{d}$ or 0.89 $\mathrm{m}^{3} /$ cow $\cdot y r$. Assuming the milking herd produces a total solids (TS) load of $5.2 \mathrm{~kg} / \mathrm{d}$ (Skerman, 2004) and spends $10 \%$ of the day at the dairy, this amounts to a sludge accumulation rate of 0.0047 $\mathrm{m}^{3} / \mathrm{kg}$ TS. This is slightly higher than the standard design rate of $0.00455 \mathrm{~m}^{3} / \mathrm{kg}$ TS for raw wastewater without solids removal pre-treatment (ASAE, 2004), which suggests that the solids trap is not performing as expected.

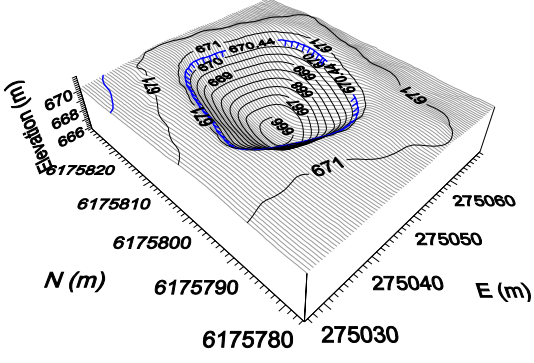

(a)

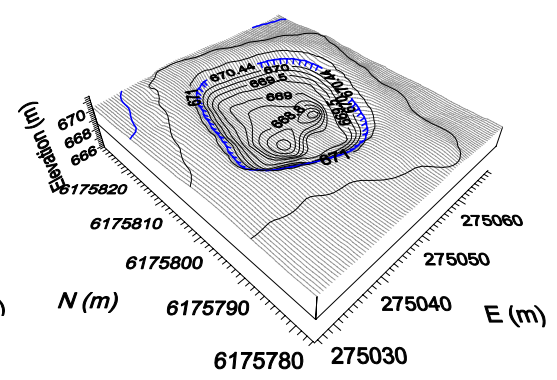

(b)

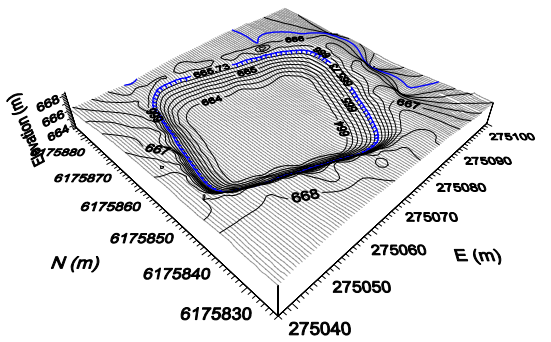

(c)

Figure 2 Surface maps (a) primary pond no sludge, (b) primary pond with $49 \%$ sludge, and (c) facultative pond.

The theoretical hydraulic retention time $\left(\mathrm{HRT}_{\mathrm{t}}\right)$ of each pond was approximated using both inflow and outflow from the two stages measured over a 150-day period. To show the likely spread of actual retention time in each pond, $\mathrm{HRT}_{\mathrm{t}}$ 's were calculated from the mean and the $25^{\text {th }}, 50^{\text {th }}$ and $75^{\text {th }}$ percentiles of the ranked daily flow data. Daily inflow data was derived from totalised 10 -second readings of instantaneous flow at the inlet to both ponds. Outflow data from the primary pond was the same as inflow to the secondary pond, while outflow from the secondary pond measured using an Emflux M300 electromagnetic flow metering system reading both the effluent recirculated to the dairy flood wash and that pumped to irrigation. The results presented in Table 1 reveal that full capacity theoretical retention times based on average flow compare favourably with recommended design values for both ponds. However, the variability of the flow through the system is likely to negatively affect treatment efficiency, particularly in the primary pond with high sludge levels. 
Table 1 Theoretical hydraulic retention times for the primary and secondary ponds

\begin{tabular}{|c|c|c|c|c|c|c|c|c|}
\hline \multirow{3}{*}{ Pond type } & \multicolumn{4}{|c|}{ Inflow } & \multicolumn{4}{|c|}{ Outflow } \\
\hline & \multicolumn{3}{|c|}{ Quartile } & \multirow{2}{*}{ Mean } & \multicolumn{3}{|c|}{ Quartile } & \multirow{2}{*}{ Mean } \\
\hline & $25^{\text {th }}$ & $50^{\text {th }}$ & $75^{\text {th }}$ & & $25^{\text {th }}$ & $50^{\text {th }}$ & $75^{\text {th }}$ & \\
\hline Primary pond full capacity (d) & 77 & 60 & 49 & 58 & 109 & 81 & 66 & 78 \\
\hline Primary pond $49 \%$ sludge (d) & 39 & 31 & 25 & 30 & 56 & 42 & 34 & 40 \\
\hline Secondary pond (d) & 203 & 151 & 123 & 146 & 351 & 235 & 153 & 137 \\
\hline
\end{tabular}

\section{Drogue tracking}

Data from the drogue tracking experiments were used to determine flow paths and velocities in the pond. Figure 3 shows the velocity vectors and pathways of drogues A, B, F, H, I, K, L, M, N, O and P. Immediately apparent from the velocity field is an overall vortex pattern similar to that observed by Shilton and Kerr (1999). The vortex is characterised by faster velocities around the perimeter of the pond from inlet to outlet (drogues A, B, I, K and L), and slower velocities associated with movement towards the centre of the pond (drogues $\mathrm{F}$ and $\mathrm{H}$ ). The faster outer pathway follows the direction of the inflow trajectory and represents a potential short-circuiting route. If influent were to move from the inlet to the outlet along this pathway (approximate total distance of $38.4 \mathrm{~m}$ ) at the average velocity of drogue $\mathrm{A}$, it could potentially reach the outlet within 45 minutes. This form of short-circuiting that follows the perimeter of the pond has been previously identified on a pond of much greater size but similar retention time by Barter (2003). It should be noted, however, that the motion of water surrounding drogue A may have been influenced by the prevailing wind which was blowing at $14.2 \mathrm{~km} / \mathrm{h}$ almost due north. Barter (2003) also found wind shear to be a minor influence on supernatant movement in areas not directly affected by mechanical mixing. As drogue A started to move in a NNE direction towards the outlet, it would have been less under the influence of the inflow 'jet' (described later) and more prone to wind-induced supernatant movement. Nonetheless, the flow path and velocity of drogue A suggest some form of short-circuiting, wind-induced or otherwise that could be further exacerbated by the high sludge level in the pond (Peña et al., 2000; Vega et al., 2003).

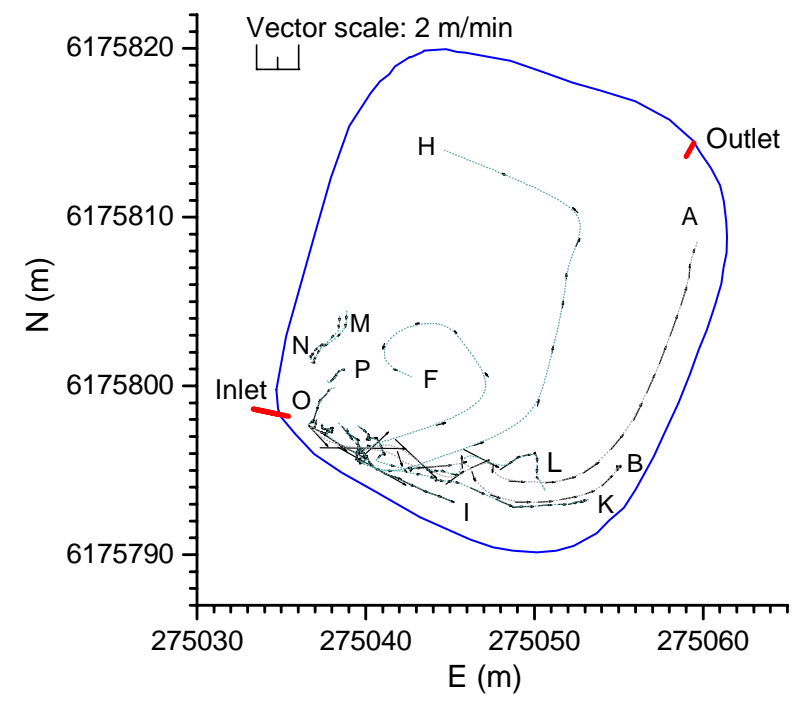

Figure 3 Velocity field incorporating drogues from all experimental runs.

A number of drogues ( $\mathrm{C}, \mathrm{E}$ and $\mathrm{J}$ - not included in the velocity field diagram) did not follow a flow path but rather oscillated within the immediate vicinity of the inlet for the entire run. This behaviour implied the formation of small eddies around where the influent pours into the supernatant from the inlet pipe which sits about $5 \mathrm{~cm}$ above the water surface. The effect of these eddies was to effectively trap the drogues in their region of influence, and sometimes pull drogues back towards the inlet (drogue G). This form of turbulence could be likened to the "back-eddy" observed by 
Shilton and Kerr (1999). Drogues D and G (also omitted from the velocity field diagram) meandered at a moderate pace following the predominant path along the southern bank, with $G$ making some movement towards the centre near the end of the run. Drogues $\mathrm{M}, \mathrm{N}, \mathrm{O}$ and $\mathrm{P}$ were placed several metres to the north of the inlet away from the trajectory of the inflow. The movement of all four drogues was very similar, each moving at a slow pace towards the inlet seemingly as part of the greater vortex mixing pattern of the pond. Table 2 provides a summary of the data from each of the drogue tracking runs. Interestingly the velocities observed in this study were of similar magnitude measured in the study by Shilton and Kerr (1999) on a facultative pond ten times the surface area, suggesting more vigorous mixing and dispersion in this anaerobic pond. Unfortunately however, Shilton and Kerr (1999) gave no indication of pond loading or retention time to provide a basis for further comparison.

Table 2 Summary of drogue movements, and wind and flow conditions for each drogue run.

\begin{tabular}{|c|c|c|c|c|c|c|c|c|c|}
\hline Date & $\begin{array}{l}\text { Drogue } \\
\text { ID }\end{array}$ & $\begin{array}{l}\text { Tracking } \\
\text { duration } \\
\text { (min) }\end{array}$ & $\begin{array}{c}\text { Total } \\
\text { distance } \\
\text { travelled } \\
(\mathrm{m})\end{array}$ & $\begin{array}{l}\text { Average } \\
\text { velocity } \\
\text { (m/min) }\end{array}$ & $\begin{array}{l}\text { Average } \\
\text { wind } \\
\text { speed } \\
(\mathrm{km} / \mathrm{h})\end{array}$ & $\begin{array}{c}\text { Wind } \\
\text { direction } \\
\text { (degrees } \\
\text { from N) }\end{array}$ & $\begin{array}{c}\text { Flood } \\
\text { wash } \\
\text { volume } \\
(\mathrm{kL})\end{array}$ & $\begin{array}{c}\text { Total } \\
\text { inflow } \\
(\mathrm{kL})\end{array}$ & $\begin{array}{c}\text { Total } \\
\text { outflow (kL) }\end{array}$ \\
\hline \multirow[t]{2}{*}{$10 / 02 / 2005$} & $A$ & 50.0 & 36.2 & 0.85 & 14.2 & 175.4 & 6.9 & 5.6 & 3.1 \\
\hline & $\mathrm{B}$ & 42.5 & 23.4 & 0.66 & 14.2 & 175.4 & 6.9 & 5.3 & 2.5 \\
\hline \multirow[t]{4}{*}{ 29/03/2005 } & $\mathrm{C}$ & 25.0 & 0.6 & 0.04 & 18.0 & 178.7 & 5.0 & 1.0 & 2.1 \\
\hline & $\mathrm{D}$ & 38.0 & 11.0 & 0.74 & 17.2 & 180.6 & 5.0 & 3.7 & 3.0 \\
\hline & $E$ & 104.0 & 2.4 & 0.11 & 9.9 & 159.4 & 3.6 & 3.3 & 10.2 \\
\hline & $\mathrm{F}$ & 102.5 & 23.9 & 0.24 & 9.9 & 159.4 & 3.6 & 3.3 & 10.2 \\
\hline \multirow[t]{4}{*}{$30 / 03 / 2005$} & G & 150.0 & 25.8 & 0.44 & 10.2 & 145.3 & 23.2 & 17.7 & 12.7 \\
\hline & $\mathrm{H}$ & 149.0 & 35.4 & 0.27 & 10.2 & 145.3 & 23.2 & 17.7 & 12.7 \\
\hline & I & 14.5 & 10.8 & 0.84 & 11.5 & 153.5 & 11.7 & 5.4 & 1.9 \\
\hline & $\mathrm{J}$ & 25.0 & 3.0 & 0.30 & 11.5 & 153.5 & 11.7 & 7.0 & 2.9 \\
\hline \multirow[t]{6}{*}{$31 / 03 / 2005$} & $\mathrm{~K}$ & 123.0 & 16.9 & 0.26 & 3.7 & 50.0 & 12.5 & 13.8 & 10.1 \\
\hline & $\mathrm{L}$ & 122.5 & 18.0 & 0.28 & 3.7 & 50.0 & 12.5 & 13.8 & 10.1 \\
\hline & $M$ & 58.5 & 4.4 & 0.09 & 4.6 & 60.4 & 10.2 & 8.1 & 5.0 \\
\hline & $\mathrm{N}$ & 59.0 & 3.6 & 0.07 & 4.6 & 60.4 & 10.2 & 8.1 & 5.0 \\
\hline & O & 40.0 & 2.9 & 0.24 & 5.2 & 69.2 & 2.3 & 6.1 & 4.1 \\
\hline & $\mathrm{P}$ & 40.5 & 1.6 & 0.08 & 5.2 & 69.2 & 2.3 & 6.1 & 4.1 \\
\hline
\end{tabular}

The main flow pattern evident from the study was that of the influent flow 'jet' that would cause drogues to move rapidly in the direction of the inflow trajectory. Within the region of influence of this jet drogues tended to reach their maximum velocity. Once drogues had moved beyond the influence of the jet, they tended to travel at a much slower, more consistent velocity, some drifting towards the centre of the pond in the vortex pattern. Figure 4 presents the plots of drogue velocity and flow for each experimental run. Of note, drogues $\mathrm{G}$ and $\mathrm{H}$ reached peak velocity almost simultaneously with peak inflow, yet quickly slowed down once they moved away from the inlet despite the inflow remaining relatively high. Moreover, they were unaffected by the second inflow surge released during their run as they had moved further away from the influent jet. Drogues $\mathrm{K}$ and $\mathrm{L}$ moved at moderate pace with a slight initial peak when closest to the inlet. They continue more slowly to a point about $6 \mathrm{~m}$ away from the inlet before being swept into motion again by an inflow surge caused by clearing the solids trap screen later in the run. Then, when a second flood wash was released (for runs $\mathrm{O}$ and $\mathrm{P}$ ) they were outside the immediate influence of the inflow jet and accordingly their velocities stayed low. Drogues M, N, O and P were placed to one side of the line of the inflow trajectory and as a result were mostly unaffected by the peak flow. The limited range of influence of the influent jet would suggest that short-circuiting is only likely to occur during very high inflow surges such as when the solids trap screen has been recently cleared, or the screen is overtopped, both of which are relatively infrequent under normal operating conditions. 

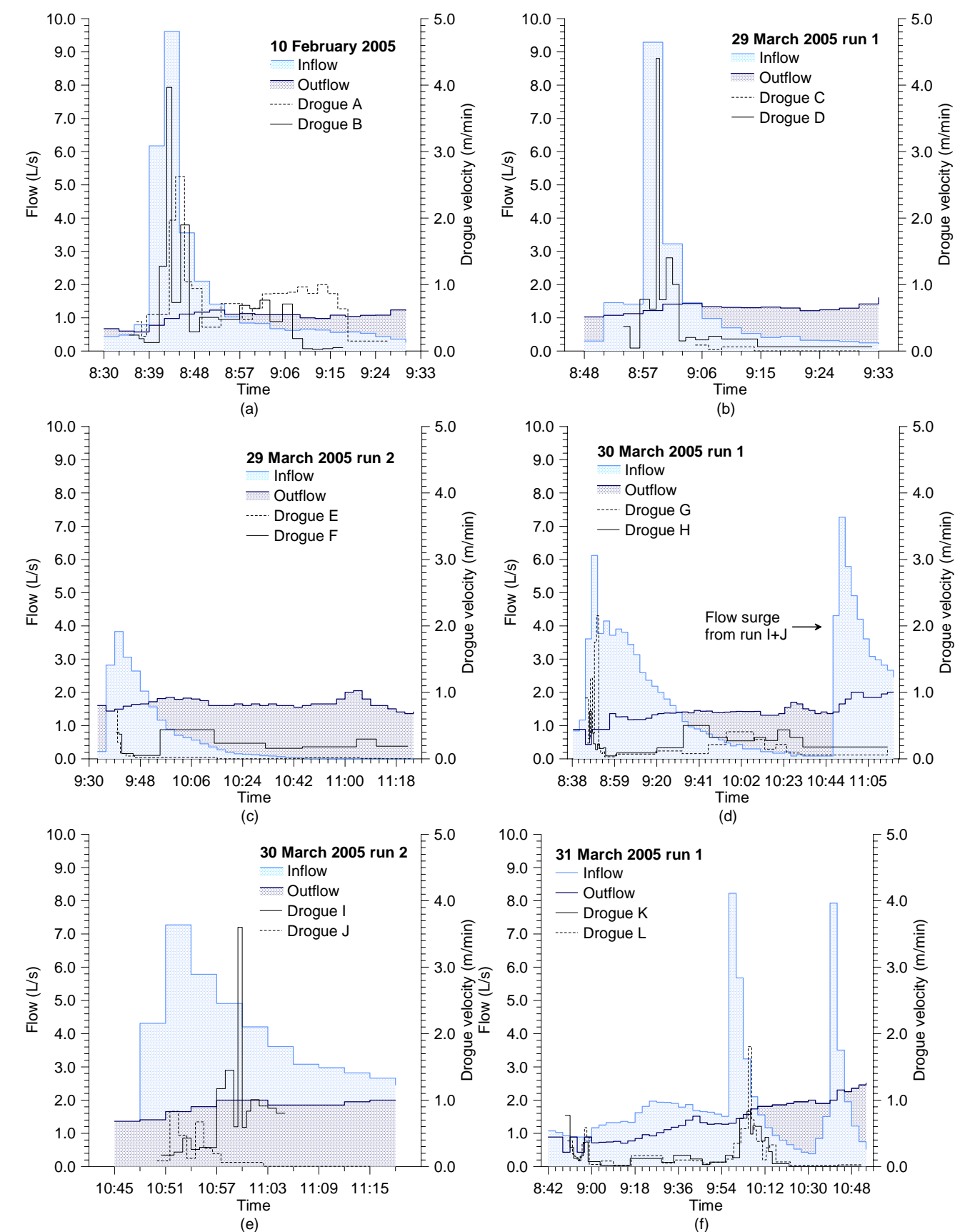

(d)
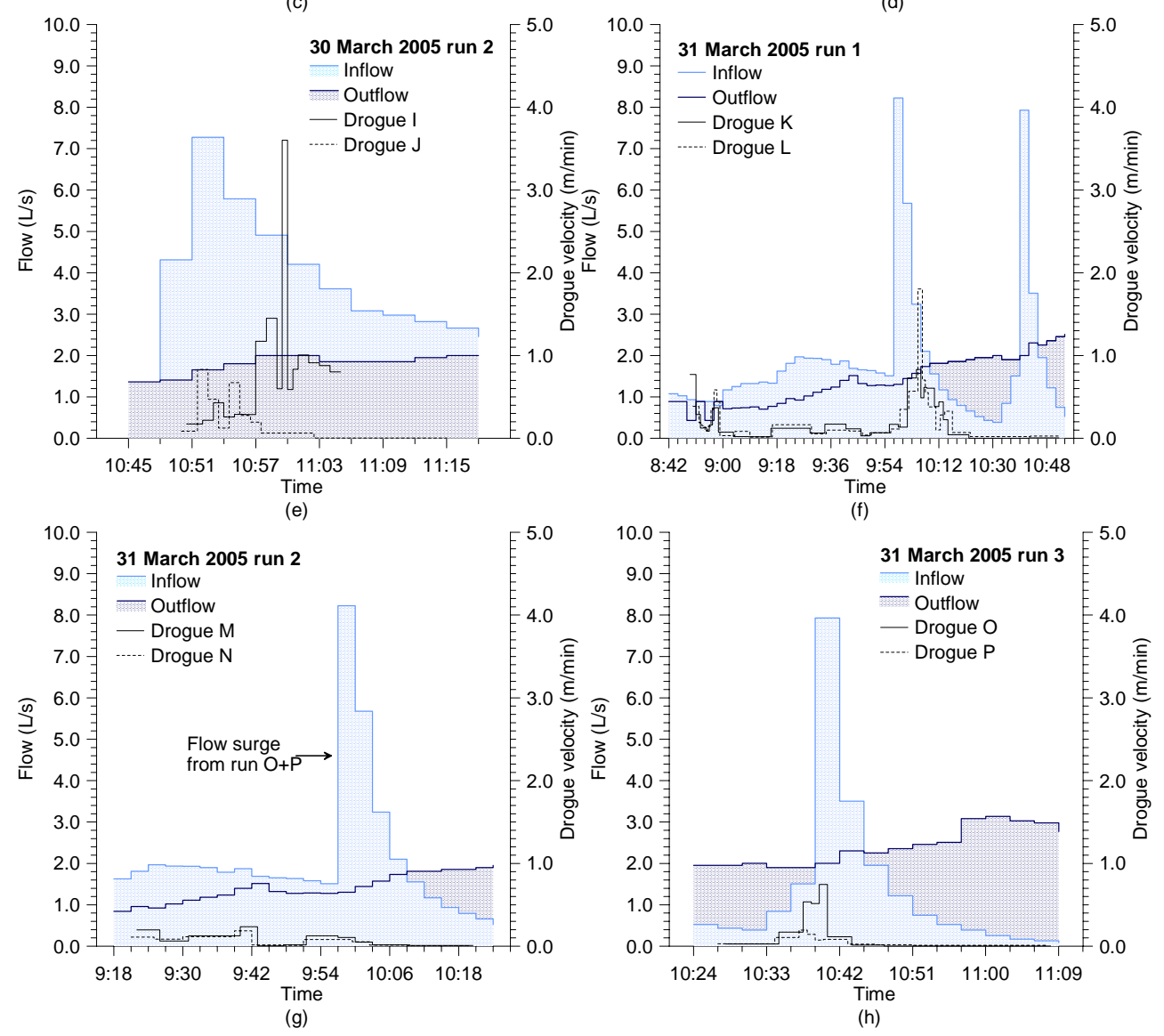

(f)

Figure 4 Plots of flow and drogue velocity with time for all experimental runs 


\section{CONCLUSIONS}

A study was undertaken to characterise the physical properties of a two-stage dairy shed waste stabilisation pond system by topographical survey and the hydrodynamic behaviour of the primary pond of the same system by drogue tracking. The topographical survey revealed significant loss of active treatment volume and reduction in retention time in the primary anaerobic pond caused primarily by the accumulation of sludge. Calculation of theoretical retention time using the mean and quartiles of in- and out-flow data showed the potential for large variations in treatment efficiency. Drogue tracking in the primary pond produced an in-pond velocity field that shows a vortex mixing pattern with a strong potential for short-circuiting caused by high velocities associated with an incoming flow 'jet' along the line of trajectory of the surging inflow. The potential for short-circuiting, however, is limited to periods of very high inflow that are likely to be relatively infrequent when the pre-treatment solids trap is effectively damping the flow rate into the pond. Regular desludging of the anaerobic pond (every three to five years) is nonetheless essential to maintaining effective treatment efficiency and a reconfiguration of the inlet and outlet arrangement along with installation of flow baffles could limit the incidence of short-circuiting.

\section{ACKNOWLEDGMENTS}

The authors would like to acknowledge the financial support given to this project by the Sydney Catchment Authority and the NSW Department of Infrastructure, Planning and Natural Resources. Also, this study has been kindly facilitated and encouraged by the farm owners, the Maloney family.

\section{REFERENCES}

ASAE Standards (2003). Design of anaerobic lagoons for animal waste management, American Society of Agricultural Engineers, St Joseph, USA, pp. 693-698.

Barter, P.J. (2003). Investigation of pond velocities using dye and small drogues: a case study of the Nelson City waste stabilisation pond. Water Science and Technology, 48(2), 145-151.

Pearson, H.W., Mara, D.D. and Bartone, C.R. (1987). Guidelines for the minimum evaluation of the performance of full-scale waste stabilization pond systems. Water Research, 21(9), 1067-1075.

Peña, M.R., Mara, D.D. and Sanchez, A. (2000), Dispersion studies in anaerobic ponds: implications for design and operation. Water Science and Technology, 42(10-11), 273-282.

Salter, H.E., Ta, C.T., Ouki, S.K. and Williams, S.C. (2000). Three-dimensional computational fluid dynamic modelling of a facultative lagoon. Water Science and Technology, 42(10-11), 335-342.

Shilton, K. and Kerr, M. (1999). Field measurements of in-pond velocities by a drogue and survey technique. Proceedings of the $4^{\text {th }}$ IAWQ Specialist Group Conference on Waste Stabilization Ponds. 1-6. Marrakech, Morocco.

Skerman, A.G. (2004). The development and use of dairy effluent calculators. The Australian Journal of Dairy Technology, 59, 182-185.

Sweeney, D.G., Cromar, N.J., Nixon, J.B., Ta C.T. and Fallowfield, H.J. (2003). The spatial significance of water quality indicators in waste stabilisation ponds - limitations of residence time distribution analysis in predicting treatment efficiency. Water Science and Technology, 48(2), 211-218.

Torres, J.J., Soler, A., Sáez, J. and Llorens, M. (2000). Hydraulic performance of a deep stabilization pond fed at $3.5 \mathrm{~m}$ depth, Water Research, 34(3), 1042-1049.

Torres, J.J., Soler, A., Sáez, J. and Ortuńo, J.F. (1997). Hydraulic performance of a deep wastewater stabilization pond. Water Research, 31(4), 679-688.

Vega, G.P., Peña, M.R., Ramirez, C. and Mara, D.D. (2003). Application of CFD modelling to study the hydrodynamics of various anaerobic pond configurations. Water Science and Technology, 48(2), 163-171.

Wood, M.G., Greenfield, P.F., Howes, T., Johns, M.R. and Keller, J. (1995). Computational fluid dynamic modelling of wastewater ponds to improve design. Water Science and Technology, 31(12), 111-118.

Wood, M.G., Howes, T., Keller, J. and Johns, M.R. (1998). Two dimensional computational fluid dynamic models for waste stabilisation ponds. Water Research, 32(3), 958-963. 